\title{
Research on the Laws of the Overlying Rock Mass Deformation of Combined Open-Pit with Underground Mining
}

\author{
SUN Shi-guo ${ }^{1}$, GUO Wei-chen ${ }^{1}$, ZHANG Yu-juan ${ }^{1}$, Wu Jun-lei ${ }^{1}$, Liu Wei-dong ${ }^{1}$
}

(North China University of Technology, Beijing 100144)

\begin{abstract}
Keywords: High and steep slope; combined open-pit with underground mining; Midas; FLAC3D; slope stability

Abstract: The slope stability problems of combined open-pit with underground mining is such a key technology and the core problem of mining safety production. This paper apply the numerical simulation analysis on engineering project, and using Midas, FLAC3D and other software analysis the slope stability, slip deformation characteristics and follow trends of combined open-pit with underground mining mining systematically. Due to the impact of both the underground mining and open-pit mining, the surface subsidence curves is multiple sink basins of different sizes, so the rock slope deformation extent of different regions is different. We find that the damage of the overlying rock is different during the the exploitation stage, indicate that with different mining thickness has important influence of the damage of the overlying rock, so the slope stability evaluation requires a combination of the specific circumstances of the project to analysis and evaluation of exploitation.
\end{abstract}

\section{Introduction}

Mineral resources is one of the pillar of the social development of our country energy, since the $1980 \mathrm{~s}$, the with the increase of open pit mining depth, the difficulty of mining gradually increased, the cost of production will increase. Using dew parallel mining of mine, therefore, increase gradually in our country, on the way to the mining of mineral resources, shallow seam strip mining method is used commonly, for deep seam, well versed in mining method has better efficiency. But for parallel mining mode, well versed in mining of open-pit slope degree, the scope, the influence of the open-pit slope deformation and destruction law research, such as is not very mature ${ }^{[1]}$.

In the process of of combined open-pit with underground mining, mining slope will be affected by two kinds of mining, open-pit mining will cause stress unloading widely in underground mining is the composite of loading and unloading, so will be affected by the two mining slope comprehensive superposition effect, known as the compound mining effect ${ }^{[2-3]}$. And under the influence of mining in the composite effect, on the slope stability analysis, should give full consideration to the two comprehensive effect produced by mining ${ }^{[4]}$. Midas, Flac3D numerical simulation analysis software is applied in this article, with purple mountain gold mine as the engineering, to simulate the sliding rule of slope under the dew parallel mining goaf overlying rock mass deformation and failure mechanism, make a comprehensive analysis of the slope stability of mining area, has decision-making guidance significance to the practical engineering.

\section{Rock mass deformation law to underground engineering example analysis}

\section{Project summary}

Purple mountain gold mine for oversize gold copper deposits in China, the design adopts the open-air underground combined mining, open pit slope design $+1096 \mathrm{~m}$, the highest elevation stope bottom elevation $+616 \mathrm{~m}$, pit covers an area of $1020 \times 700 \mathrm{~m} 2$, covers an area of $184 \times 85 \mathrm{~m} 2$, bottom slope design gold at the end of the biggest difference is $486 \mathrm{~m}$, belongs to the high and steep slope ${ }^{[5]}$. Among them, the copper deposits are mainly distributed in the mines in the north west structural fissure zone, with concealed seems very thick bedded and lenticular overlay form output, and occurs in gold lower NE lateral tilt direction. Relatively thick orebody overburden, vertical below are widespread in the bottom of a gold mine LouCaiKeng about $50 \mathrm{~m}$ tall no ore interval ${ }^{[6]}$.

Adopted by the numerical simulation of mechanical parameters of rock mechanics experimental 
results, and considering the purple mountain gold mine geological exploration previous records. Specific mechanical parameters as shown in table 2.1, of which the code I group on behalf of the hard rock block Mosaic structure, Mosaic structure III representative soft rupture rock group, IV represent extremely soft symmetrical dispersed structure cataclastic rock group.

Table 1 The rock mechanics parameters of ZiJinShan gold and copper mine

\begin{tabular}{llllll}
\hline & $\begin{array}{l}\text { Modulus of } \\
\text { elasticityE/ } \\
\text { Gpa }\end{array}$ & $\begin{array}{l}\text { Poisson's } \\
\text { ratio } \\
\text { Parameters of rock mass } \\
\text { Mechanical parameters }\end{array}$ & $\begin{array}{l}\text { Bulk } \\
\text { density } \gamma( \\
\left.\mathrm{KN} / \mathrm{m}^{3}\right)\end{array}$ & $\begin{array}{l}\text { Cohesion } \\
\mathrm{C}(\mathrm{MPa})\end{array}$ & $\begin{array}{l}\text { Angle of } \\
\text { internal } \\
\text { friction } \varphi{ }^{\circ}\end{array}$ \\
\hline $\begin{array}{l}\text { In the fine grained granite } \\
\text { in the breeze I }\end{array}$ & 38.5 & 0.31 & 29.4 & 0.70 & 39.0 \\
$\begin{array}{l}\text { Strong in fine grained } \\
\text { granite weatheringIII }\end{array}$ & 27.3 & 0.23 & 26.2 & 0.15 & 27.3 \\
$\begin{array}{l}\text { Strong weathering of fine } \\
\text { grained graniteIV }\end{array}$ & 32.8 & 0.22 & 25.2 & 0.114 & 33.04 \\
$\begin{array}{l}\text { Dacite-porphyrite } \\
\text { Cryptoexplosive breccia }\end{array}$ & 37.9 & 0.26 & 26.4 & 1.26 & 30.45 \\
$\begin{array}{l}\text { The copper body } \\
\text { Loose waste slag }\end{array}$ & 94.3 & 0.29 & 26.9 & 1.11 & 33.7 \\
\hline
\end{tabular}

\section{Numerical analysis of combined open-pit with underground mining}

Numerical model of the purple mountain, a related geological data and the present situation of mining, the purple mountain gold mine stope complex geological conditions, the dew parallel adopt numerical simulation to select lithology weaker 4-4 section, as shown in figure 1, in order to different lithology meshing area and gives corresponding rock mechanics properties, relatively rigorous two-dimensional model is established. The $2 \mathrm{~d}$ model extension $400 \mathrm{~m}$ along the $\mathrm{Y}$ axis, the corresponding $3 \mathrm{~d}$ model is set up. Because of the purple mountain gold mine geological condition is relatively complex, finally numerical simulation model has 77742 nodes and 77742 units.

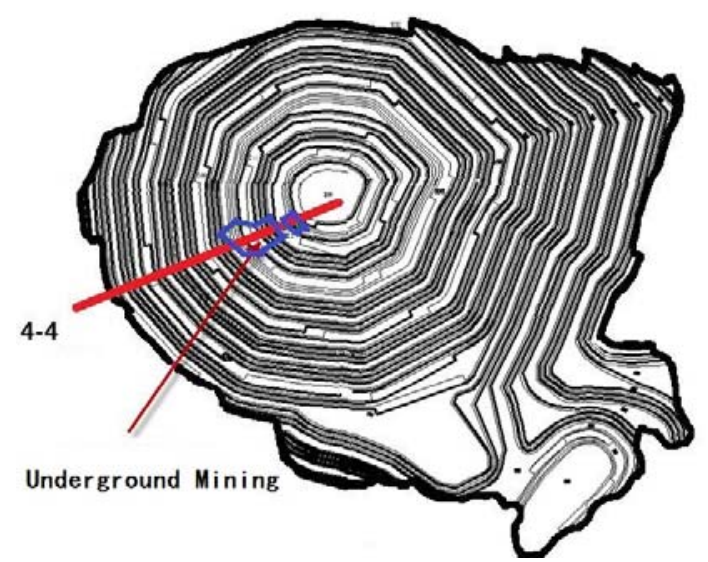

Figure 1 numerical simulation profile selection diagram

In order to study the dew under parallel mining damage rule of slope rock mass of slide for gob caving method and filling method were used respectively to compare the processing conditions of slope stability study

The main simulation process is:

1) open-pit and underground mining simultaneously, open to $100 \mathrm{~m}$ by $604 \mathrm{~m}$ excavation, mining $84 \mathrm{~m}$, each phase six stages to complete.

2) the underground mining by $100 \mathrm{~m}$ to $150 \mathrm{~m}$, is divided into five excavation stage is completed, $100 \mathrm{~m}$ and $50 \mathrm{~m}$ phase respectively, $50 \mathrm{~m}$ to $0 \mathrm{~m}$ phase, $0 \mathrm{~m}$ to $50 \mathrm{~m}$ phase, to $50 \mathrm{~m}$ to $100 \mathrm{~m}$ phase, phase of - $100-\mathrm{m}$ to $150 \mathrm{~m}$. 
3) excavation in goaf are numerically simulated respectively, and the two kinds of processing methods for gob caving method is used to deal with the first, the second for using waste slag filling mined-out area. As shown in figure 2

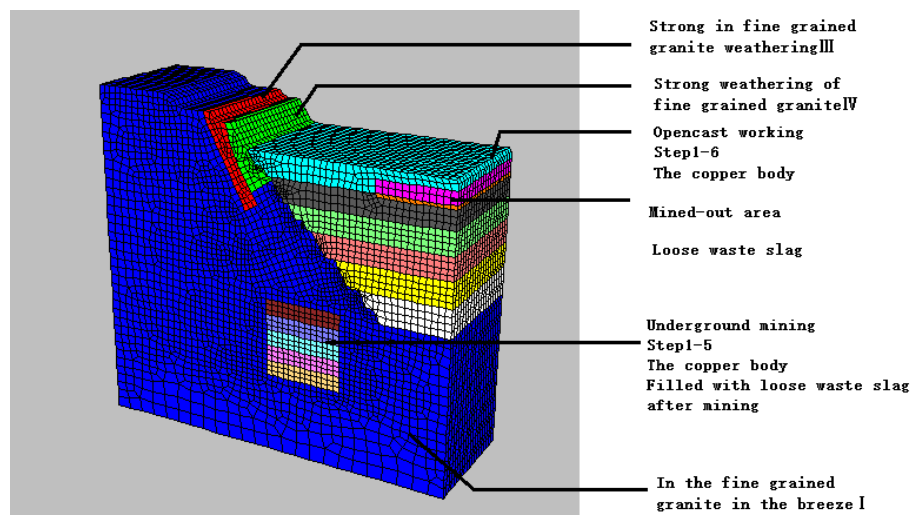

Figure 2, 4-4 section parallel mining diagram

By looking at the caving method and treatment of mined-out area of the results of numerical simulation, from the stages of displacement field can be seen after mining with the deepening of mining stage, the influence of underground mining to slope rock mass scope expanding gradually, and has a tendency to accelerate. Mined-out area influence basic covers the whole slope rock mass, slope rock mass by partial buckling deformation gradually, eventually extended to the buckling deformation of large area. Deformation of slope by underground mining of main control function, maximum displacement is $69.1 \mathrm{~m}$, slope type belongs to collapse. As shown in figure 3 .

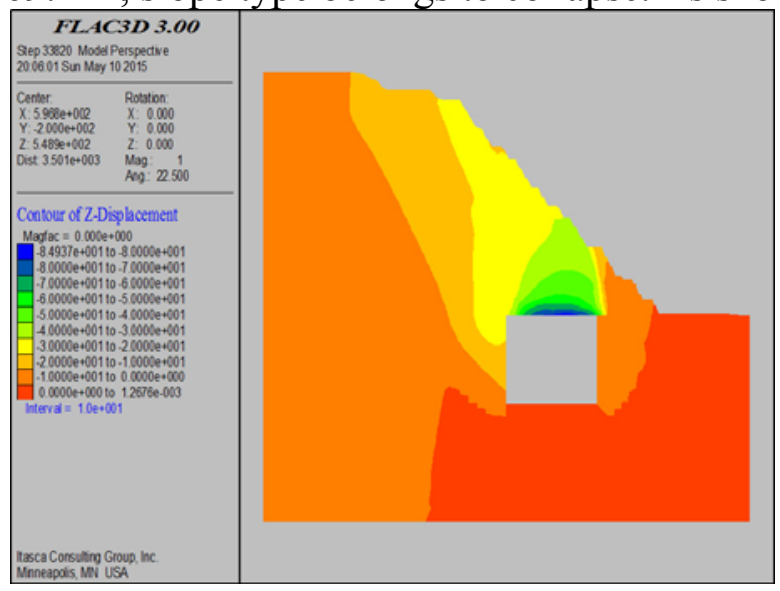

Figure 3 caving method and treatment of mined-out area vertical displacement nephogram

From goaf filling and excavation of stress field and displacement field cloud cloud can be seen that the goaf filling after underground mining of open-pit slope body have larger decrease, the influence of slope rock mass basic maintain overall stability at the beginning, and then produce a shift in local, local damage after the excavation slope rock mass, the need for reinforcement. Slope of open-pit and underground mining complex, the maximum displacement of $6.2 \mathrm{~m}$, slope belongs to slip collapse destroyed. As shown in figure 4. 


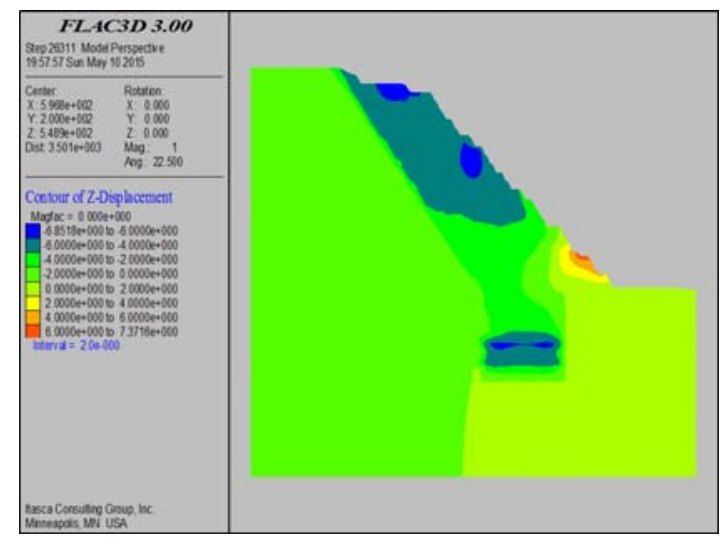

Figure 4 filling method and treatment of mined-out area in vertical direction displacement nephogram

Two goaf treatment methods to extract the settlement curve as shown in figure 5, figure 6 , you can see caving method and treatment of mined-out area is not desirable processing method, by contrast filling method and treatment of mined-out area has a better control effect on the overall stability of the slope, and analyzing the characteristics of the curve can be found, in dew parallel mining process, the compound effect due to underground mining and open pit, the surface subsidence curve is not simple curve of subsidence basin, certainly will appear many small area subsidence basin, slope rock mass sliding may also become more area of small scale.

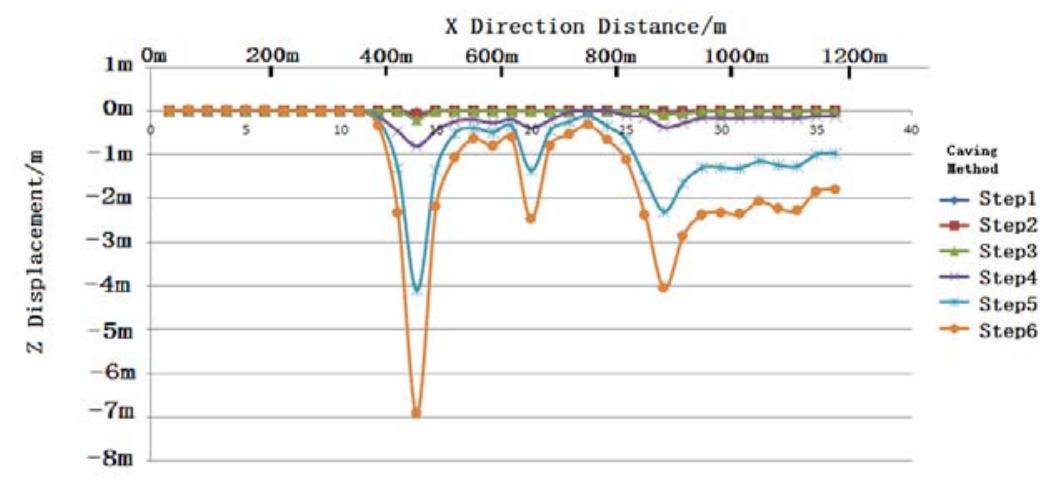

Figure 5 caving method, the surface subsidence displacement curve

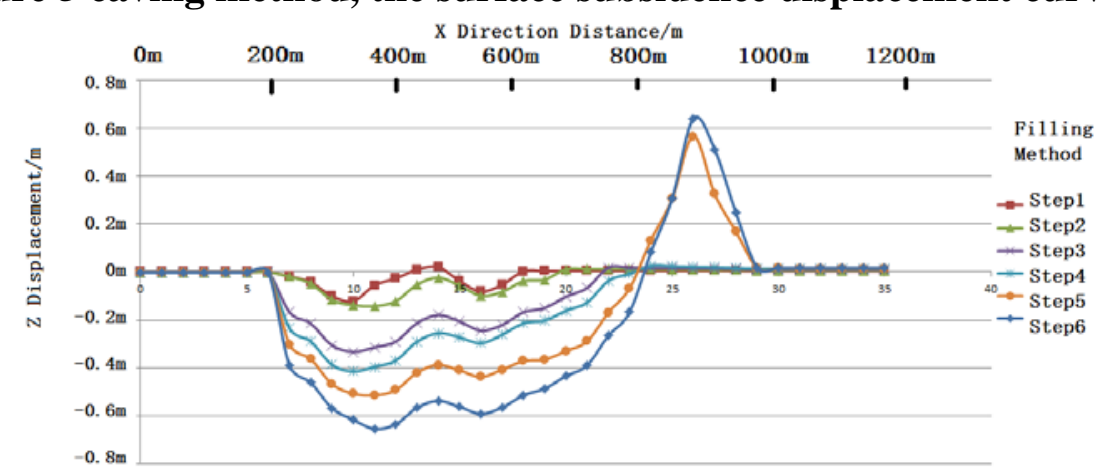

Figure 6 pack method subsidence of surface displacement curve

\section{Summary}

Through practical engineering, analysis in goaf under the different processing methods of numerical simulation results, can draw the following conclusion:

1 , the purple mountain gold mine goaf can be treated by caving method, the underground mining subsidence control role of slope rock mass, open-air excavation effect on rock mass movement is small, the slope body of maximum subsidence value reached $69.1 \mathrm{~m}$, above goaf. After two stages during mining slope rock mass are in a state of flux, $50 \mathrm{~m}$ mining to $-100-\mathrm{m}$ phase slope rock 
mass of whole produce damage, the larger area of possible landslides, goaf treatment is not recommended.

2, using filling mining, slope rock mass joint control function by open-air excavation and underground mining, underground mining have less effect on the slope, the slope rock mass maximum subsidence value is $6.2 \mathrm{~m}$, is located in the top area. Mining to $50 \mathrm{~m}-100-\mathrm{m}$ phase, the slope rock mass of local damage occurs, the need for reinforcement.

3 , in dew parallel mining process, the compound effect due to underground mining and open pit, the surface subsidence curve is not simple curve of subsidence basin, certainly will appear many small regional subsidence basin, slope rock mass sliding may also become more area of small scale.

\section{Acknowledgments}

The first author: Sun Shi-guo(1959- ), male,Postdoctoral. The professor of the northern industrial unive rsity majoring in civil engineering construction engineering college level discipline responsibility, $d$ octoral supervisor.Mine safety and the northern industrial university institute of geotechnical engine ering.

Fund project: This research has been funded by The National Natural Science Foundation of China (No.41172250), National five-year science and technology support project(2012BAK09B06), The in novative team project of Beijing (IDHT20140501), The scientific research base construction, scienti fic research innovation platform, scientific research and special - impact pressure build of microseis mic monitoring and early warning system(XN083)and New type of anchor reinforcement technique field test research and graduate student ability training(XN107).

\section{References}

[1]Sun Shiguo, Zhao Xuefang, Wang Qun. Influence of Different Mining Sequence of Steeply Inclined Orebody on Overlying Rock Mass Deformation [J]. China's Mining Industry, 2015, 46 (3): 106-110.

[2].(Cui Yuzhu. Numerical modeling of continuum and discontinuous media and its application to safety analysis of arch dam-foundation systems[Ph. D. Thesis][D]. Beijing Tsinghua University 2001.(in Chinese)).

[4]XU Nianchun. Research on multi-parameter inversion for rock mass joint using reflected wave[D].Chongqing:Chongqing University.College of Civil Engineering,2007.

[5] Itasca Consulting Group Inc. Itasca. 3DEC three-dimensional distinct element code Version 3.0 user's manual[R]. [s. 1. ] Itasca Consulting Group Inc. USA 1988. 